\section{(6) OPEN ACCESS}

\title{
Does prompt treatment of urinary tract infection in preschool children prevent renal scarring: mixed retrospective and prospective audits
}

\author{
Malcolm G Coulthard, ${ }^{1}$ Heather J Lambert, ${ }^{1}$ Susan J Vernon, ${ }^{1}$ Elizabeth W Hunter, ${ }^{2}$ \\ Michael J Keir, ${ }^{3}$ John N S Matthews ${ }^{4}$
}

${ }^{1}$ Paediatric Nephrology Unit, Great North Children's Hospital, Newcastle, UK ${ }^{2}$ Paediatric Radiology Department, Great North Children's Hospital,

Newcastle, UK

${ }^{3}$ Department of Regional Medical Physics, Royal Victoria Infirmary, Newcastle, UK ${ }^{4}$ School of Mathematics and Statistics, Newcastle University, Newcastle, UK

\section{Correspondence to} Dr Malcolm G Coulthard, South Park House, South Park, Hexham, Northumberland NE46 1BS, UK; malcolm. coulthard@nuth.nhs.uk

Received 10 May 2013 Revised 1 November 2013 Accepted 1 December 2013 Published Online First 18 December 2013

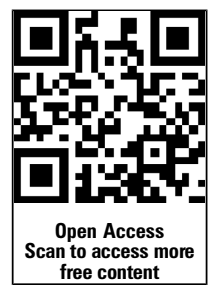

To cite: Coulthard MG, Lambert HJ, Vernon SJ, et al. Arch Dis Child

2014;99:342-347.

\begin{abstract}
Objective To test whether active management of urinary tract infections (UTI) in young children by general practitioners can reduce kidney scarring rates.

Design A comparison of two audits in Newcastle, of children aged $<8$ years, presenting with UTIs ; a retrospective audit of conventional management during 1992-1995 (1990s) versus a prospective audit of direct access management during 2004-2011 (2000s).

Main outcome measures Kidney scarring rates, and their relationship with time-to-treat.

Results Children with a first UTI in the 2000s compared to those in the 1990s, were referred younger, were half as likely to have a renal scar (girls OR 0.47, $95 \% \mathrm{Cl} 0.29$ to 0.76 ; boys $0.35,0.16$ to 0.81 ), and were about 12 times more likely to have vesicoureteric reflux without scarring (girls 11.9, 4.3 to 33.5; boys $14.4,4.3$ to 47.6 ). In the 2000 s, general practitioners treated about half the children at first consultation. Children who were treated within 3 days of their symptoms starting were one-third as likely to scar as those whose symptoms lasted longer $(0.33,0.12$ to 0.72).
\end{abstract}

Interpretation Most kidney defects seen in children after UTIs, are acquired scars, and in Newcastle, active management in primary care has halved this rate.

\section{INTRODUCTION}

Until 2007, most GPs had based their management of childhood urinary tract infections (UTI) upon the 1991 guidelines. ${ }^{1}$ We published general practitioners' (GP) practices ${ }^{2}$ and referral, and kidney scarring rates $^{3}$ in 1997, and then introduced an alternative direct-access (DA) management system which integrated primary and secondary care. Here, a nurse-coordinator encouraged more active diagnosis, treatment and direct referral for renal imaging, with paediatricians becoming involved only in abnormal cases. A randomised controlled trial in 2003 showed that children were referred younger, and infants were identified with vesicoureteric reflux (VUR) without scarring. ${ }^{4}$ We speculated, controversially, ${ }^{5}$ that they may have had scarring prevented by very prompt antibiotic prescribing, ${ }^{6}$ supported by animal ${ }^{7}{ }^{8}$ and clinical evidence $^{9}$ that suggests a therapeutic window of $\leq 3$ days. Newcastle then introduced the DA model as a service provision, and we prospectively audited its impact from 2004.

Part-way through this audit, National Institute for Health and Care Excellence (NICE) ${ }^{10}$ and others, ${ }^{11}$ introduced unpiloted guidelines which

\section{What is already known on this topic}

- Recent childhood urinary tract infection (UTI) guidelines presume that few kidney defects can be prevented, and strive to minimise renal tract imaging.

- All published childhood UTI guidelines advise prompt treatment, but none provide target times.

\section{What this study adds}

- Treating children's urinary tract infections in $\leq 3$ days, more than halves the risk of them acquiring kidney scars.

- GPs can halve the kidney scarring rates in young children by active management using a direct-access service.

- This reduction in scarring rates could not have been detected if the National Institute for Health and Care Excellence guidelines had been implemented locally.

were designed to reduce the imaging burden. ${ }^{12}$ When they were implemented in other parts of our health region, they changed clinical practice in a way that would have prevented us from completing our study, so we agreed not to introduce them until our audit was finished. These are our results.

\section{PATIENTS AND METHODS}

1990s: We retrospectively audited the 154000 children aged < 16 years in Newcastle and adjacent health districts during 1992-1995 with a first recognised UTI, ${ }^{3}$ as defined in figure 2 . All were imaged according to 1991 recommendations ${ }^{1}$ with an ultrasound and delayed dimercaptosuccinic acid (DMSA) scan, while infants $<1$ year and children who presented and had recurrences while aged between 1 year and 4 years also had a micturating cystogram (MCUG).

2000s: The Newcastle primary care trust adopted our published DA model ${ }^{4}$ as their service for 70800 children managed by GPs, walk-in centres and emergency departments. We prospectively audited its impact on children born from 01/ 01/2004, which did not require ethics committee 
approval. The 1990s imaging protocol was only modified by replacing MCUGs with indirect radionuclide mercaptoacetyltriglycine (MAG3) cystography for children aged over 3.5 years. ${ }^{13}$

The DA service nurse encourages GPs to commence antibiotics on clinical suspicion of a UTI immediately after a diagnostic urine sample has been collected, and then to stop in culture-negative cases. She encourages the use of a urine phase-contrast microscopy service in the hospital's acute assessment unit to assist in making rapid, confident diagnoses in some cases. ${ }^{14}$ She also telephones for full details of incomplete referrals, to provide feedback, and to continually update training. We recorded the time (days) between the GP's estimate of the onset of symptoms and attendance at surgery (attendance interval) and from then to the prescription of antibiotics (prescription interval), and summed them to define the total symptom-to-prescription interval.

We assume that children with VUR exposed to further UTIs are at risk of acquiring new scars, so we counsel parents to seek medical attention quickly if more symptoms occur, including providing DA to our acute urine microscopy service, ${ }^{14}$ until their reflux resolves (tested by 4 -yearly MAG3 cystograms). We offer low-dose (1-2 mg/kg) night-time trimethoprim prophylaxis in the hope of reducing UTI recurrences. If recurrences do occur, we check for new scarring using DMSA.

Data: In the 1990s, we examined a mean of 9376 children per year group for 4 years. In the 2000 s, there were a mean of 4426 children in each year-group, but because we only audited children born after the DA service was established, we followed the children born in 2004 for up to 8 years, those born in 2005 for up to 7 years, and so on. Hence, we studied around 35200 children during their first year of life, 30800 during their second year, down to just over 4400 during their eighth year.

\section{Analysis}

We have analysed the girls' and boys' data separately as they have different risk factors for UTIs. The probabilities of referral were estimated using population sizes and, for those aged $\leq 8$ years, compared between the 1990s and 2000s using a likelihood ratio test which assumed that the counts followed a Poisson distribution and which allowed for the different observation patterns outlined above. The incidence of focal scars and of VUR among those referred was assessed using a logistic regression model which allowed for the age of the child as well as the difference between the 1990s and 2000s. To avoid problems of convergence with the small numbers of cases in some analyses, the models were fitted using Firth's bias-corrected method $^{15}$ using the programme brglm ${ }^{16}$ in R.
Within the 2000s cohort, referral and treatment intervals were compared between children with different imaging outcomes using a cumulative proportional odds model for ordinal data, ${ }^{17}$ fitted using the programme polr in $\mathrm{R}^{18}$

\section{RESULTS}

\section{Referrals}

Similar proportions of children aged $<8$ years were referred with UTIs during the 1990 s and 2000 s (girls $8.7 \%$ vs $10.6 \%$; boys $3.0 \%$ vs $3.1 \%$ ), but they were referred younger in the 2000s (figure 1; likelihood-ratio test, $\mathrm{p}<0.001$ for both). In total, 2262 children were imaged during the 1990s, and 1664 during the 2000s (figure 2).

\section{Focal scars}

The number of children with focal DMSA defects consistent with renal scarring fell from the 1990s to the 2000s (girls, $0.43 \%$ to $0.18 \%$; boys $0.14 \%$ to $0.05 \%$; black bars in figure 3 ). Those referred with a UTI during the 2000 s were less than half as likely to have a scar as earlier (age-adjusted OR 0.47 and $95 \%$ CI 0.29 to $0.76, p=0.002$ for girls; 0.35 , and 0.16 to $0.81, \mathrm{p}=0.014$ for boys).

Thirty children had scarred kidneys in the 2000s cohort, of which $4(13 \%)$ were bilateral. Of 34 scarred kidneys, 22 (65\%) had multiple defects, and 8 (24\%) had ultrasound abnormalities. One 4-year-old girl had severe hypertension which resolved after unilateral nephrectomy, and an 18-month-old boy had bilateral scarring and chronic renal impairment. Of the 25 scarred children tested for VUR, 15 were positive ( 7 bilaterally), mostly at grades ${ }^{19} 2$ or 3 (table 1). Two of five children followed up by MAG3 cystography have outgrown their reflux. Five toddlers with scars have not had an MCUG, but are being managed as if they do have reflux until they are old enough to cooperate with MAG3 cystography.

\section{VUR without scarring}

During the 1990s, three infants had isolated grade 2 VUR without scarred kidneys (approximately $0.02 \%$ of girls and $0.01 \%$ of boys; grey bars in figure 3 ), which they outgrew without acquiring any scars. During the 2000s, this had risen to 103 children (66 girls), approximately $0.39 \%$ of girls and $0.22 \%$ of boys. Children referred now are about 12 times more likely to have isolated VUR than previously (age-adjusted OR 11.9 and $95 \%$ CI 4.3 to $33.5, \mathrm{p}<0.001$ for girls; 14.4 , and 4.3 to $47.6, \mathrm{p}<0.001$ for boys). Most presented aged $<1$ year, and all were $<4$ years old. The reflux was bilateral in 59 , and of
Figure 1 Cumulative referral rates of girls and boys with a urinary tract infection (UTI) in Newcastle, using a conventional UTI management model up to the age of 16 years during 1990s (open circles), and using the direct access model up to the age of 8 years during the 2000 s (filled circles).
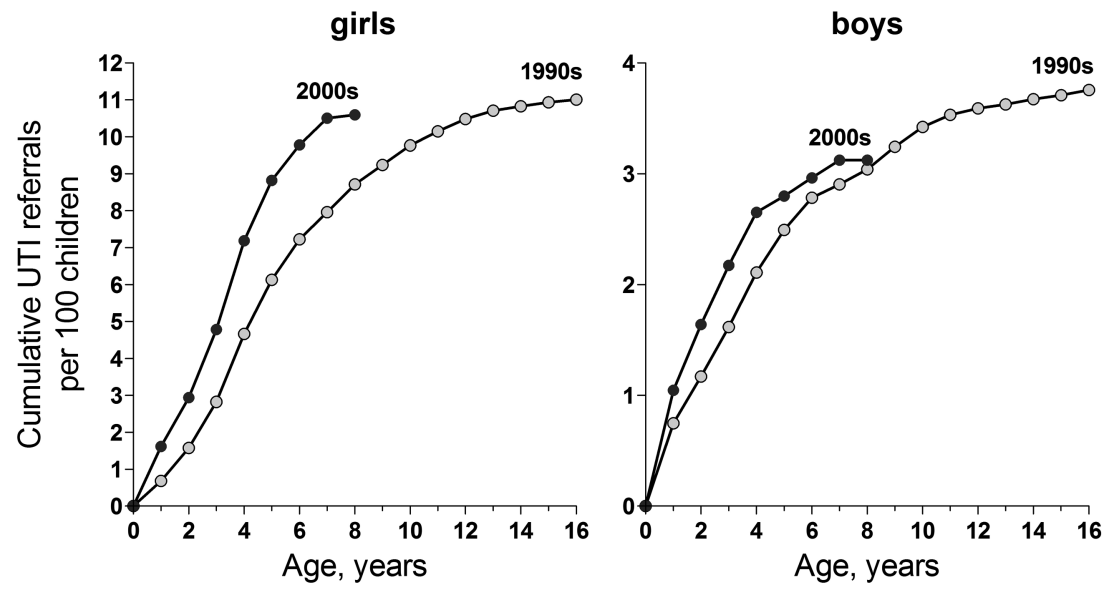


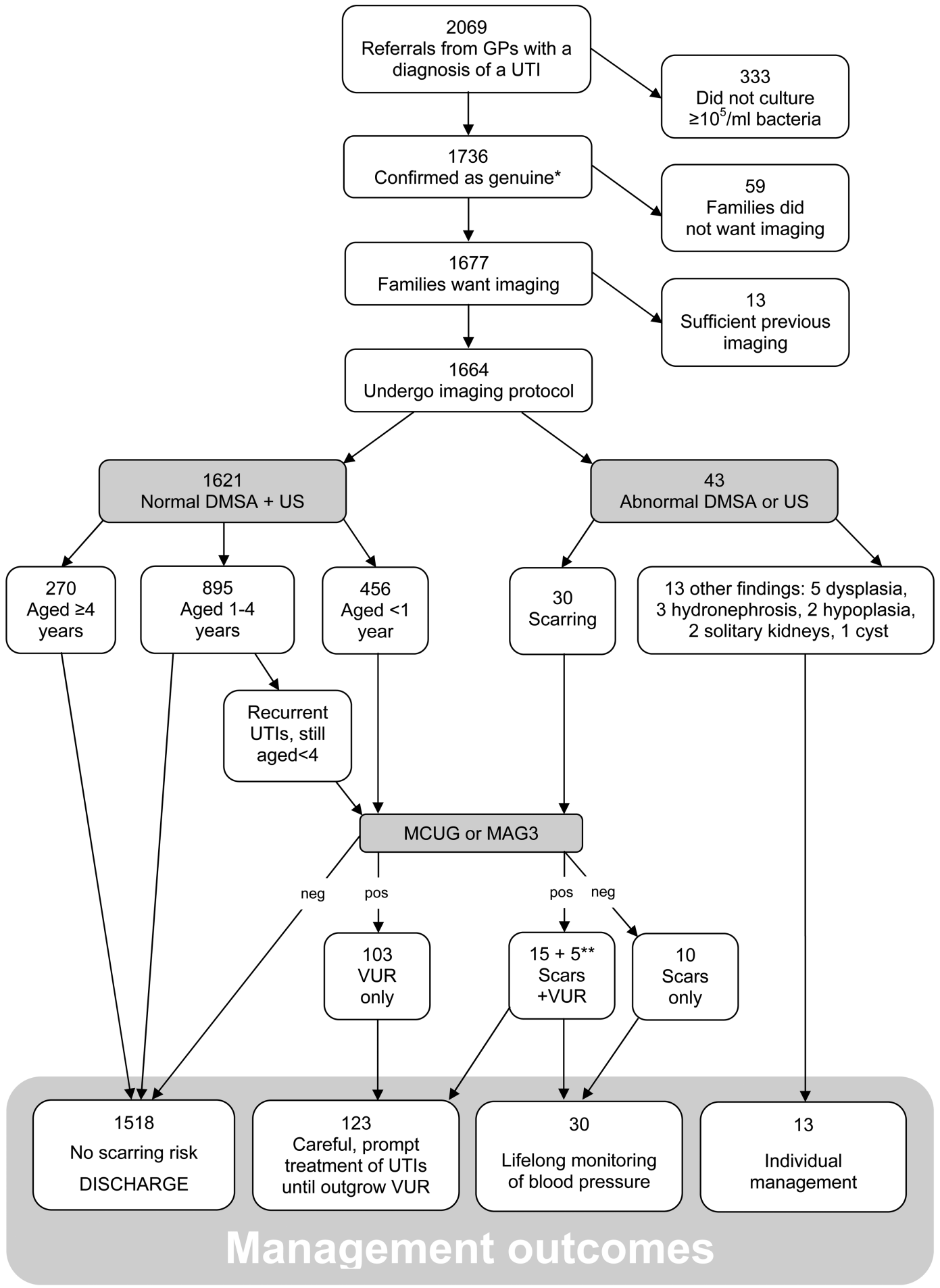

Figure 2 Flow chart showing the imaging and management outcomes (both shaded in grey) of 2069 children born after 1 January 2004 , that were referred to the direct access service in Newcastle with a possible urinary tract infection, through 2011 . * Defined as a pure growth of $\geq 10^{5} / \mathrm{mL}$ of E coli, Proteus, Klebsiella, Pseudomonas or Enterococcus species. ** Five children have not been tested for vesicoureteric reflux(VUR) yet; being treated clinically as if they have VUR, and will have a delayed MAG3.

similar severity to that in the children with scarring (table 1). Ultrasound examination showed dilatation in eight children, and a staghorn calculus in 1 .

Twenty-five children with isolated VUR have had recurrent UTIs, of which 24 started treatment the day their symptoms began. One child who repeatedly presented after long delays had her VUR treated by endoscopic submucosal injection.
All have normal repeat DMSA scans. Of 30 so far tested by MAG3 cystography, 18 of them have outgrown their reflux.

\section{Other abnormalities}

During the 2000s, 13 children (approximately 0.03\% of girls and $0.05 \%$ of boys) had the following renal tract abnormalities; gross ureteric dilatation and bilateral renal dysplasia in 5 (3 with 

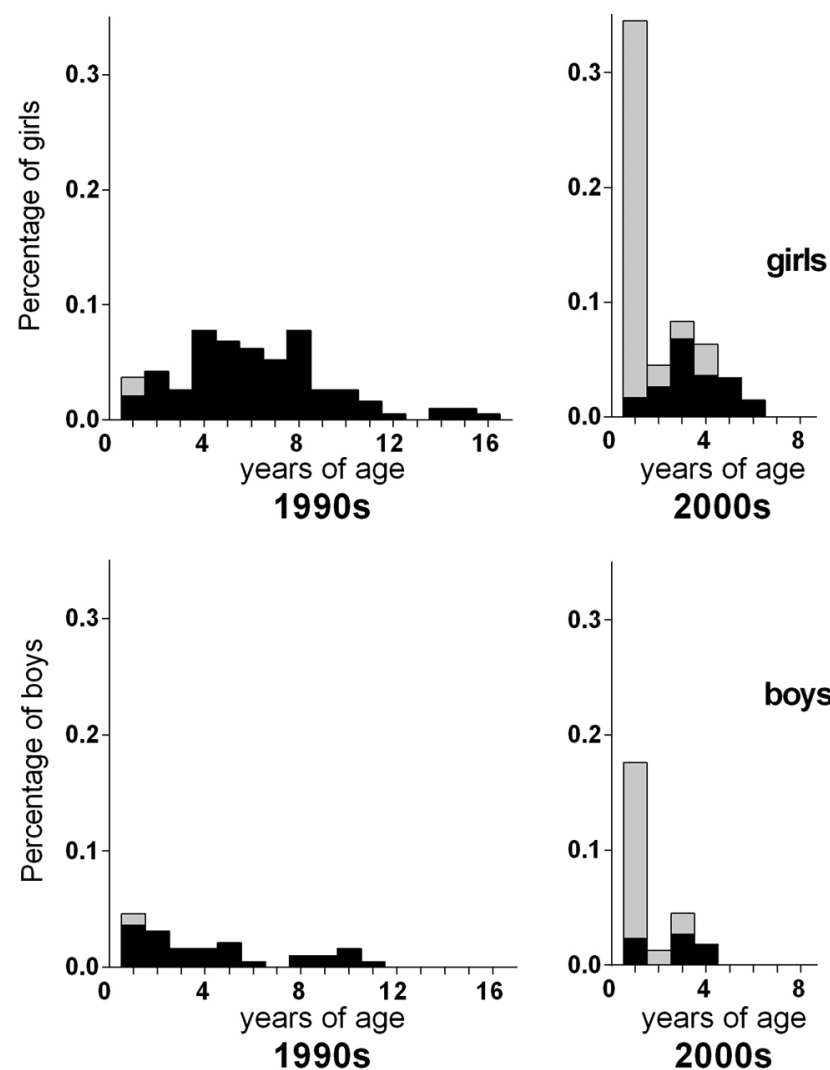

1990s

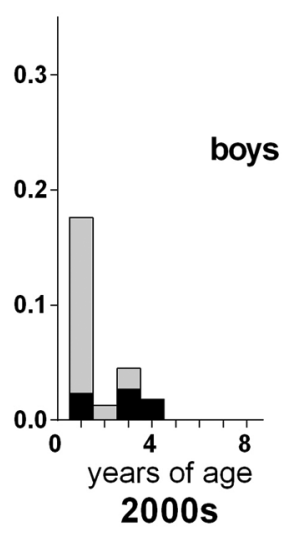

VUR only

Figure 3 Percentage rates for focal scarring (black bars) and isolated vesicoureteric reflux (grey bars) among girls and boys in Newcastle after a urinary tract infection. The left-hand charts are for conventional management during the 1990s, and the right-hand charts are for direct access during the 2000s.

bilateral VUR), mild hydronephrosis (3), hypoplasia (2), solitary kidneys (2), or a simple parenchymal cyst (1).

\section{Referral patterns in the 2000s}

The attendance, treatment and total symptom to treatment intervals from $95.6 \%$ of the 2000 s children are plotted in figure 4 , according to their imaging results.

Attendance interval: Children with isolated VUR were seen by the GP sooner than those with normal kidneys (OR 0.63, $95 \%$ CI 0.42 to $0.93, p=0.017)$, while those with scars were seen later (OR 2.86, 95\% CI 1.41 to 5.88, $\mathrm{p}=0.003$ ), and this was independent of the day of the week their symptoms began. Sixty-nine per cent of children with isolated VUR attended on the day their symptoms began, as did 58\% with normal imaging, and $33 \%$ with scarred kidneys. The audit was not designed to discern causes of these differences, but 6/30 children with scars had correspondence in their medical records about social issues, compared to $1 / 103$ children with isolated VUR (OR 26, 95\% CI 3 to $1176, \mathrm{p}=0.001$ ).

Treatment interval: The treatment interval did not differ between the three patient groups $(\mathrm{p}=0.15$, likelihood-ratio test), and was generally short. Around half were prescribed antibiotics on the day they presented, and three-quarters within 3 days.

Symptom to treatment interval: The total symptoms to treatment interval was very similar for patients with normal kidneys
Table 1 The grades of VUR detected in the ureters of children with and without renal scarring in the 2000s, and their scarring risks

\begin{tabular}{lrrrrrr}
\hline & \multicolumn{2}{l}{ With scarring } & & \multicolumn{2}{l}{ Without scarring } & Scarring risk \\
Grade of VUR & $\mathbf{n}$ & Per cent & & $\mathbf{n}$ & Per cent & Per cent \\
\hline 1 & 2 & 9 & & 32 & 19 & 6 \\
2 & 11 & 50 & & 110 & 68 & 9 \\
3 & 5 & 23 & & 19 & 12 & 21 \\
4 & 3 & 14 & & 1 & 1 & 75 \\
5 & 1 & 5 & & 1 & 1 & 50 \\
\hline & VUR, vesicoureteric reflux. & & &
\end{tabular}

and isolated VUR (OR 1.00, 95\% CI 0.70 to $1.43, \mathrm{p}=0.99$ ), but was longer for patients with scars (OR 2.70, 95\% CI 1.33 to $5.56, \mathrm{p}=0.006$ ). Children treated within 3 days of their symptoms starting had less than half the chance of being scarred than those treated from day 4 onwards (OR $0.37,95 \%$ CI 0.18 to $0.75, \mathrm{p}=0.006$ ).

\section{DISCUSSION}

These data support our hypothesis ${ }^{6}{ }^{20}$ that most kidney defects seen on DMSA scans in children after UTIs are acquired scars, with only a small proportion being congenital. It also demonstrates that the scarring rate has halved since the GPs changed their management from traditional ${ }^{2}$ to more active practices, ${ }^{4}$ including (A) very prompt treatment, and (B) targeting resources on children who remain at risk until they outgrow their VUR. The GPs sustained these changes throughout the audit, probably aided by the specialist nurse's ongoing educational input. They consistently diagnosed more UTIs in young infants (often with non-specific symptoms), collected urine samples (aided by family friendly urine pads ${ }^{21}$ in infants, and washed-up potties ${ }^{22}$ in toddlers), and prescribed antibiotics at the first consultation in half the cases. We doubt that the Newcastle GPs' management of childhood UTIs in the 1990s differed from other areas of the UK, where most first recognised episodes are also in school-aged children. ${ }^{23}{ }^{24}$ However, patterns of early diagnosis have been reported from Sweden for 20 years. ${ }^{25}$ The attendance interval varied widely, and was an important factor for scarring risk, with children treated four or more days after their symptoms had started being twice as likely to scar.

It is a weakness that our two audits were not contemporaneous, and did not cover identical catchment areas. However, our 1990s data did not demonstrate any geographically related differences in referral or scarring rates, and the UTI management protocol remained static apart from the introduction of the DA element, which had previously been shown to produce immediate and sustained changes in GP behaviour. ${ }^{4}$ This audit was only made possible because the primary and secondary care teams agreed not to implement the CG54 guidelines without first measuring their impact. Because we encourage starting antibiotics on clinical grounds prior to laboratory confirmation, some children will inevitably receive unnecessary treatment, with the potential to cause avoidable side effects and increased resistance to the antibiotic. We did not design our audit to detect this, although we know that $16 \%$ of children referred were treated inappropriately, and the true figure could be much higher. Nor did we design our audit to determine which factors influenced the time taken for children to present for medical care, other than noting that the day of the week was unimportant. 

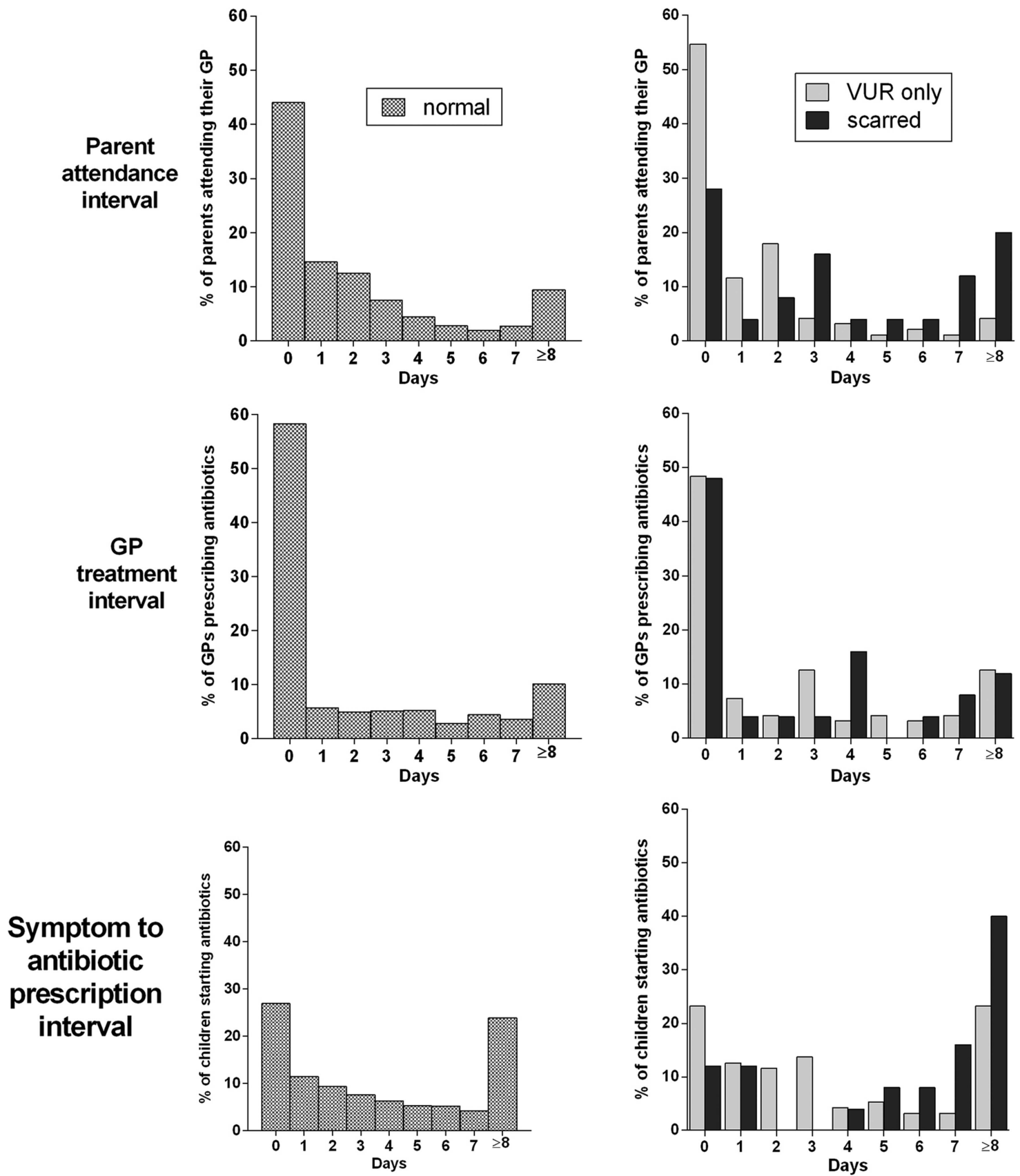

Normal imaging

\section{Abnormal imaging}

Figure 4 Number of days of intervals for parents to take their child with a urinary tract infection to their GP after the onset of their first symptoms, the interval for the GPs to then prescribe antibiotics, and the total days between the child developing symptoms and being prescribed antibiotics. The left-hand charts refer to children with normal renal tract imaging. On the right, the grey bars are for children with isolated vesicoureteric reflux, and the black ones are children with focal scars.

The causative role of infection combined with VUR in producing scarring has been questioned ${ }^{5}$ because many paediatric reports (including our 1990s audit ${ }^{3}$ ) have found that most renal parenchymal defects are present after the child's first recognised UTI, and because until now there has been insufficient evidence that scars can be prevented by active management. Instead, many now consider that reflux and parenchymal defects may congenitally codevelop. If true, it would follow that active management and extensive imaging guidelines are inappropriate. ${ }^{10-12}$ However, we have shown here that very prompt active management reduces the number of children identified with DMSA defects, and more are recognised with VUR but no scarring. This is consistent with animal studies which have shown that treating UTIs within 3 days also prevents scarring. ${ }^{7} 8$ One clinical study which concluded that prompt treatment does not reduce renal scarring was restricted to a highly selected subgroup of children who had pyelonephritis and an abnormal acute DMSA scan, and may therefore not be applicable to unselected children with a UTI. ${ }^{26}$ Studies on the value of prophylactic antibiotic treatment remain inconclusive. $^{27}$ We currently offer prophylaxis to families, but acknowledge that educating primary care teams and families 
about the importance of responding urgently to possible recurrences, using a rapid diagnostic service, may be more valuable. We have found this approach to be highly effective for all children with VUR under our care, including those identified by screening because of a family history of VUR. ${ }^{28}$

To replicate the Newcastle experience of halving the number of children developing kidney scars would require doctors to manage young children with UTIs more actively, and to reflect this in national guidelines. ${ }^{10}{ }^{11}$ Especially important would be the need to establish treatment time-scale targets with strategies to achieve them while minimising antibiotics overuse, including promoting accurate rapid diagnosis with easy-access phasecontrast microscopy services to immediately exclude most uninfected samples and reduce contamination rates. ${ }^{14}$ Also, imaging protocols would need to be altered to allow targeted management, and to determine when children outgrow their VUR, and the risk of acquired scarring. An alternative strategy to minimise imaging by treating every child with a very severe UTI urgently, at any age, ${ }^{9}$ would in the UK require additional resources and infrastructure. Sustaining this vigilance without knowing a child had an increased personal scarring risk may be difficult. The morbidity caused by paediatric kidney scarring is mainly seen in adult life (though hypertension and chronic renal failure were identified in children in this audit), when the typical picture of 'chronic pyelonephritis' evolves. Our DA primary care catchment population forms approximately $10 \%$ of the old UK Northern Health Region, and within that, approximately one adult per month receives a kidney transplant for pyelonephritis, while many more wait on dialysis. We hope that these numbers will decrease in the future by actively managing small children with UTI.

Our findings raise many important questions. Perhaps the most important is how low can the kidney scarring rate fall? Could some or all the children who were treated at $\geq 4$ days and who had scarring have had this prevented by earlier treatment, and if so how could this be best achieved? Our data suggest that we need especially to develop strategies to reduce the time that some parents take to present to the primary care physicians. Also, although most children were treated very promptly after presentation, a substantial number were not managed so quickly. We plan to undertake future studies to evaluate the factors that influence both these time intervals. We also plan to measure the extent of antibiotic overprescribing that our approach generates, and how it can be minimised.

Contributors MGC and HJL conceived the idea of undertaking the project. MGC, HJL, SJV, EWH and MJK all designed the project and collected data. MGC drafted the article and JNSM undertook the statistical analysis of the data. All the authors reviewed the article for important intellectual content and approved the final version for publication. MGC is guarantor.

\section{Competing interests None.}

Provenance and peer review Not commissioned; externally peer reviewed.

Open Access This is an Open Access article distributed in accordance with the Creative Commons Attribution Non Commercial (CC BY-NC 3.0) license, which permits others to distribute, remix, adapt, build upon this work non-commercially, and license their derivative works on different terms, provided the original work is properly cited and the use is non-commercial. See: http://creativecommons.org/ licenses/by-nc/3.0/

\section{REFERENCES}

1 Royal College of Physicians Research Unit Working Group. Guidelines for the management of acute urinary tract infection in childhood. J $R$ Coll Physicians Lond 1991;25:36-42.

2 Vernon S, Foo CK, Coulthard MG, et al. How general practitioners manage children with urinary tract infection: an audit in the former Northern Region. Br J Gen Pract 1997:47:297-300.

3 Coulthard MG, Lambert HJ, Keir MJ, et al. Occurrence of renal scars in children after their first referral for urinary tract infection. BMJ 1997;315:918-19.

4 Coulthard MG, Vernon SJ, Lambert HJ, et al. A nurse led education and direct access service for the management of urinary tract infections in children: prospective controlled trial. BMJ 2003;327:656-59.

5 Venhola M, Uhari M. Vesicoureteral reflux, a benign condition. Pediatr Nephrol 2009:24:223-26

6 Coulthard MG. Vesicoureteric reflux is not a benign condition. Pediatr Nephrol 2009;24:227-32

7 Glauser MP, Meylan P, Bille J, et al. The inflammatory response and tissue damage: the example of renal scars following acute renal infection. Pediatr Nephrol 1987:1:615-22.

8 Slotki IN, Asscher AW. Prevention of scarring in experimental pyelonephritis in the rat by early antibiotic therapy. Nephron 1982;30:262-68.

9 Coulthard MG, Verber I, Jani JC, et al. Can prompt treatment of childhood UTI prevent kidney scarring? Pediatr Nephrol 2009;24:2059-63.

10 National Institute for Health and Care Excellence (NICE). Urinary tract infection in children. 2007. http://guidance.nice.org.uk/CG054

11 American Academy of Pediatrics. Urinary tract infection: Clinical practice guideline for the diagnosis and management of the initial UTI in febrile infants and children 2 to 24 months. Pediatrics 2011;128:595-610.

12 Tullus K. What do the latest guidelines tell us about UTIs in children under 2 years of age. Pediatr Nephrol 2012;27:509-11.

13 Keir MJ, Lambert HJ, Coulthard MG. Maximising the sensitivity of the indirect radionuclide cystogram: a retrospective audit. Pediatr Nephrol 2013;28:2137-41.

14 Coulthard MG, Nelson A, Smith T, et al. Point-of-care diagnostic tests for childhood urinary tract infection: phase-contrast microscopy for bacteria, stick-testing, and counting white blood cells. J Clin Pathol 2010;63:823-9.

15 Firth D. Bias reduction of maximum likelihood estimates. Biometrika 1993;80:27-38

16 Kosmidis I. brglm: bias reduction in binary-response GLMs. $R$ package version 0.5-5. 2007. http://www.ucl.ac.uk/ ucakiko/software.html

17 McCullagh P. Regression models for ordinal data. J R Stat Soc 1980; series B 42:109-42.

18 Venables WN, Ripley BD. Modern applied statistics with S. 4th edn. New York: Springer, 2002

19 International Reflux Study Committee. Medical versus surgical treatment of primary vesico-ureteral reflux. Pediatrics 1981;67:392-400.

20 Coulthard MG. Do kidneys outgrow the risk of reflux nephropathy? Pediatr Nephrol 2002:17:477-80

21 Liaw LCT, Nayar DM, Pedler SJ, et al. Home collection of urine for culture from infants by three methods: survey of parents' preferences and bacterial contamination rates. BMJ 2000:320:1312-13.

22 Rees J, Vernon S, Pedler $S$, et al. Collecting urine from washed-up potties. Lancet 1996;348:197.

23 Jadresic L, Cartwright $\mathrm{K}$, Cowie $\mathrm{N}$, et al. Investigation of urinary tract infection in childhood. BMJ 1993;307:761-64.

24 Paed L, Maskell R. Study of urinary tract infection in children in one health district. BMJ 1994;309:631-4.

25 Jakobsson B, Soderlundh S, Berg U Diagnostic significance of 99mTc-dimercaptosuccinic acid (DMSA) scintigraphy in urinary tract infection. Arch Dis Child 1992;67:1338-42.

26 Hewitt IK, Zucchetta P, Rigon L, et al. Early treatment of acute pyelonephritis in children fails to reduce renal scarring: data from the Italian renal infection study trials. Pediatrics 2008;122:486-90.

27 Mattoo TK. Evidence for and against urinary prophylaxis in vesicoureteral reflux. Pediatr Nephrol 2010;25:2379-82.

28 Scott J, Swallow V, Coulthard MG, et al. Screening of newborn babies for familial ureteric reflux. Lancet 1997:350:396-400. 